\title{
Da competição à cooperação: Economia Solidária como proposta sustentável para os novos rumos da humanidade
}

From competition to cooperation: Solidarity Economy as a sustainable proposal for the new directions of humanity

\section{Matheus Pedrosa Silva da Costa matheuspedrosa01@gmail.com}

Graduando em Psicologia pela Pontifícia Universidade Católica do Rio de Janeiro PUC-Rio.

\section{Ruth Espínola Soriano de Mello Orientadora ruthm@prof.iag.puc-rio.br}

Doutora em Ciências Sociais pela Pontifícia Universidade Católica do Rio de Janeiro PUC-Rio.

\section{Resumo}

Este artigo estabelece relações entre a noção de competição e altruísmo na evolução e em sociedade. A partir da problemática do aumento das desigualdades, analisa distinções entre o modelo atual de organização socioeconômica e os fundamentos básicos da economia solidária. Apresenta essa como uma alternativa viável frente aos desafios contemporâneos inerentes ao modelo atual baseado na competição, consumismo e individualismo.

Palavras-chave: competição; desigualdade social; Nova Economia; cooperação; Economia Solidária.

\begin{abstract}
This article establishes relationships between the notion of competition and altruism when it comes to evolution and society. Based on the problem of increasing inequalities, it analyzes distinctions between the current model of socioeconomic organization and the basic foundations of solidarity economy. Therefore, this article presents it as a viable alternative to the contemporary challenges inherent to the current model based on competition, consumerism and individualism.
\end{abstract}

Keywords: competition; social inequality; New Economy; cooperation; Solidarity Economy. 


\section{Introdução}

O atual modelo de organização social e econômica se baseia, majoritariamente, na competição e disputa entre sujeitos por oportunidades de exploração de recursos. Essa dinâmica é ainda mais acentuada no mercado de trabalho, em que as ofertas de emprego exigem prérequisitos que nem sempre estão de acordo com as condições sociais daqueles que almejam uma vaga (Santos et al., 2016). Situação que corrobora os mecanismos de empobrecimento da maioria da população e, consequentemente, o aumento das desigualdades. Seguindo o modelo hegemônico, as empresas tendem a metrificar e controlar as relações de trabalho por meio de metas e objetivos predefinidos, renunciando a sua função social (Almeida, 2003). Desse modo, seguindo a lógica da meritocracia, aqueles que atingem as métricas são valorizados pelo mercado e têm maiores chances de progredir na carreira. Já quem permanece aquém das médias produtivas tende a ser mantido em posições menos favorecidas, exercendo o trabalho como modo de subsistência, tendo inclusive agravos à saúde mental relativos à preocupação constante de perda do emprego (Alves; Neto, 2019).

No que tange ao trabalho no Brasil, de acordo com dados da Pesquisa Nacional por Amostra de Domicílios (PNAD) do Instituto Brasileiro de Geografia e Estatística (IBGE), em março de 2020, a taxa da população brasileira ocupada foi a menor de toda série histórica iniciada em 2012. Analogamente, o rendimento real habitual reduziu-se neste ano quando comparado ao mesmo período do ano passado. Certamente, a crise sanitária, humanitária e econômica relacionada à Sars-CoV-2 potencializou o aumento das taxas de desemprego e ampliação das desigualdades no Brasil. Todavia, cabe ressaltar que esses processos já estavam em curso no país mesmo antes da pandemia (Carvalho, 2019). Atualmente, o indicador de concentração de renda (índice Gini) do Brasil permanece um dos piores do mundo e, segundo estudos do Instituto Brasileiro de Economia da Fundação Getúlio Vargas (FGV/IBRE, 2019), permanece ascendendo - o que demonstra o aumento da desigualdade no país.

Nesse contexto, o estudo propõe uma reflexão do panorama atual, apresentando, de forma breve, teorias que apoiam a visão da sociedade como meio de constante disputa. Traçando um paralelo entre a competição e o altruísmo, focando na importância do último para vida em comunidade e associando esse aos princípios da economia solidária por meio de estratégias orientadas a atitudes e práticas colaborativas e fraternas. Endossa, por fim, a necessidade de estudos subsequentes sobre o tema, em especial, em áreas relacionadas às ciências humanas e sociais, principalmente no campo do conhecimento do empreendedorismo social. 


\section{Teorias clássicas}

Após sua viagem ao redor do mundo e depois de anos de trabalho na catalogação das espécies, Charles Darwin (1809-1882) foi capaz de sistematizar e apresentar dados defendendo a teoria da evolução. A partir dela, demonstrou a continuidade entre as espécies sustentando que o Homo Sapiens é uma entre as demais. Para tal, se baseou na ideia da natureza como um sistema pautado no estado permanente de disputa entre espécies, sendo a manutenção da vida o maior imperativo biológico dos seres vivos. Ademais, apresentou a noção de seleção natural, de modo que os mais adaptados ao ambiente tendem a se manterem vivos e, consequentemente, perpetuar a espécie disseminando seus caracteres à prole (Darwin, 1859).

No que se refere às bases para sustentação da teoria, Darwin foi influenciado pelo economista e político Thomas Malthus (1766-1834), que afirmava que a vida em sociedade implicava na assunção da luta constante por sobrevivência, em que somente os mais fortes resistem. Baseando-se nessa ideia, Malthus sugeria que as políticas públicas de bem-estar aos pobres do século XVIII seriam um modo de contribuir para o aumento desses, diminuindo o padrão de vida da população geral da Grã-Bretanha na época (Goodwin, 2010). Para sustentar tais afirmações, Malthus propunha que, na ausência de guerras e epidemias, a taxa populacional tenderia a um crescimento geométrico, já a produção de alimentos cresceria de forma aritmética. Logo, a consequência de tal disparidade seria um desequilíbrio do sistema socioeconômico, ocasionando fome, miséria e gerando importantes disputas sociais. Na sua obra, Darwin apresenta a aplicação da teoria malthusiana no mundo animal:

É a doutrina de Malthus aplicada com a mais considerável intensidade a todo o reino animal e vegetal, porque não há nem produção artificial de alimentação, nem restrição ao casamento pela prudência. Posto que algumas espécies se multiplicam hoje mais ou menos rapidamente, não pode ser o mesmo para todas, porque a terra não as poderia comportar. (Darwin, 1859, p.78)

Essa passagem demonstra de modo categórico a influência da noção malthusiana da vida como luta pela sobrevivência na teoria darwiniana da evolução. No entanto, Darwin acrescenta uma particularidade à sua proposição ao enfatizar a importância do ambiente no processo evolutivo, afirmando que as espécies são adaptadas a um determinado meio, portanto, não são mais fortes que outras. Desse modo, não incorpora em absoluto o conceito de Malthus de que somente os fortes sobrevivem. Para Darwin, são os mais adaptados que se perpetuam (Darwin, 1859). O autor enfatiza a importância da competição para a evolução das espécies: posto que 
os recursos são finitos, é a disputa por eles que mantém o equilíbrio do ecossistema por meio do controle das populações. Logo, a competição seria o modo de evitar as previsões malthusianas no habitat animal.

Na sociedade atual, as previsões de Malthus não se confirmaram. A população mundial não está dobrando a cada ciclo de vinte e cinco anos (conforme previsto) e a produção de alimentos é a maior de toda história (Fontana et al., 2015). No entanto, ainda hoje, a fome e desnutrição são uma realidade no mundo, o que, indubitavelmente, demonstra que a questão está para além da relação matemática entre população e alimentação. Cabe ressaltar que as ideias malthusianas foram estabelecidas no zeitgeist da revolução industrial, e dificilmente se poderia antever os avanços técnicos-científicos que permitiram o controle da natalidade e a otimização da produção de alimentos, principalmente em países desenvolvidos (Goodwin, 2010). Contudo, tais ideias foram empregadas de modo político, sustentando discursos e modelos econômicos excludentes pautados na manutenção das disparidades amparada pela suposta falta ou escassez de recursos. Segundo Pereira e Marin (2017), a lei da escassez foi, e ainda é, um dos marcos no estudo das ciências econômicas. De acordo com a teoria, esse fenômeno é criado e solucionado (equilibrado) pelo próprio mercado. Acerca dessa questão os professores desenvolveram um trabalho que discorre sobre os paradigmas econômicos clássico, neoclássico e seus impactos:

Seja considerando o indivíduo como homo economicus ou como "homem contratual", o mainstream parte do princípio metodológico de que o comportamento dos indivíduos é regido pela "lei da escassez", desconsiderando que a ação dos indivíduos possa ser ela mesma responsável pela escassez, quando esta ocorre. Abandonar em definitivo a "teoria neoclássica" implicaria, entre outras coisas, compreender que a economia não é regida por uma "lei da escassez" que implica entender o comportamento como escolha racional. (Pereira \& Marin, 2016, p.19)

Portanto, a escassez seria uma condição gerada pelas ações individuais e não uma lei determinista a qual todo processo de desenvolvimento econômico deveria se basear. Sobre esse fenômeno, pode-se citar como exemplo o aumento dos preços dos produtos de limpeza durante os meses de março e abril, por conta da procura exacerbada devido às inseguranças relacionadas à quarentena do coronavírus. Nesse caso, a escassez não era base, sua ocorrência se deu pela expressiva demanda daqueles que compraram grandes quantidades para estocagem. Fato que, consequentemente, zerou os estoques dos mercados, aumentou os preços e reduziu a possibilidade de compra de outras famílias. Assim como produtos de limpeza, definitivamente, no Brasil e no mundo não faltam recursos. Na prática, existem desafios relacionados à 
distribuição das riquezas, promoção do acesso equânime às oportunidades incluindo o direito básico à saúde e educação. É importante refletir sobre os ideais que perpetuaram, e ainda perpetuam, o juízo de que as dificuldades econômicas de um determinado país estão diretamente ligadas ao tamanho de sua população. Ou que a sociedade deve ser predatória e excludente, já que "somente os mais fortes terão sucesso".

Cabe ressaltar que Darwin, ao se aproximar da noção de luta pela sobrevivência e de disputa constante entre as espécies, gera, por consequência, uma questão ao paradigma da evolução. Por quais razões uma determinada espécie deixaria de ter uma vantagem para ajudar outra, sendo os recursos limitados? Os comportamentos altruístas, em especial, quando impactavam negativamente uma determinada espécie eram uma incógnita. Na atualidade, os seres humanos mantêm seus traços pró-sociais e altruístas de modo individual. No entanto, as pressões capitalistas pelo consumo tendem a perpetuar atitudes de competição e comparação social, o que corrobora com a normalização e incentivo ao consumismo. Assim, o ato de consumir, ao se tornar corriqueiro e natural, gera a ilusão da ausência de impactos à comunidade e ao meio ambiente advindos de tais práticas.

\section{O paradoxo do desenvolvimento}

Diferentemente daquilo com que Charles Darwin se preocupava, na atualidade não é por conta da reprodução descontrolada dos animais que a Terra sofre sérios danos, mas sim devido ao consumo exacerbado dos seres humanos. Sobre essa questão, o historiador Yuval Noah Harari sustenta que o Homo Sapiens é a espécie mais devastadora à natureza quando comparada a todas outras criaturas vivas (Harari, 2018). Essa afirmação permite a reflexão de como os seres humanos têm uma tendência narcísica, de se ver para além da natureza. Tal visão legitima o Sapiens a utilizar os recursos naturais, incluindo outros seres vivos, como bens em prol do desenvolvimento econômico. Apesar das críticas à espécie, o autor enfatiza a capacidade do ser humano para observar o passado e repensar seus atos na busca por desfechos alternativos.

Sobre a história da economia, Harari endossa a importância da teoria econômica clássica de Adam Smith (1723-1790). Citando a obra A Riqueza das Nações, explica a revolução que estas ideias provocaram na sociedade da época. Yuval sublinha a importância da noção que os lucros poderiam ser reinvestidos nos próprios negócios, gerando novas tecnologias, empregos e progresso econômico. Em vista disso, a riqueza individual adquire extrema relevância para 
comunidade. Logo, ser rico implicaria, teoricamente, em uma responsabilidade social e coletiva.

A afirmação de Smith de que o desejo humano egoísta de aumentar o lucro privado é a base para a riqueza coletiva é uma das ideias mais revolucionárias na história humana (...). O que Smith afirma é, na verdade, que a ganância é algo bom e que ao ficar mais rico eu benefício a todos, e não só a mim mesmo. Egoísmo é altruísmo. (Harari, 2018, p.417)

As ideias de Smith foram a base para economia e estão presentes até a atualidade e, assim como as de Malthus, precisam ser estudadas e repensadas. Cabe ressaltar que, nesse esforço, se deve evitar o anacronismo, ou seja, avaliar e criticar ideias de séculos passados com base nas informações e noções do tempo atual. Entretanto, a atualidade demonstra que os lucros dos negócios, em sua maioria, estão sendo massivamente acumulados. Prova disso são as fortunas cada vez maiores associadas ao aumento do número de bilionários no mundo. Segundo dados do mais recente relatório da ONG Oxfam (baseado no Credit Suisse Research Institute's Global Wealth Databook e lista de bilionários da Forbes, 2019), 1\% da população mais rica acumula mais de $60 \%$ de toda riqueza mundial. É esse abismo socioeconômico que gera o paradoxo do desenvolvimento, visto que o progresso ocorre, mas não para a maioria.

De fato, no último século ocorreram grandes avanços científicos e tecnológicos, além de inúmeros progressos sociais, como a consolidação dos direitos humanos fundamentais. Todavia, no que tange à distribuição de riquezas alguns avanços parecem, curiosamente, exacerbar as disparidades. Como exemplo se pode citar o progresso tecnológico e seus impactos no mercado de trabalho. Novas tecnologias, como a automação, tendem a fechar diversos postos de emprego, principalmente em indústrias. Ademais, tais avanços impulsionam a contratação de mão de obra cada vez mais especializada, corroborando com a fragmentação do trabalho por áreas de domínio. Nesse contexto, aqueles que têm a oportunidade de se profissionalizarem poderão conquistar bons empregos. Em oposição àqueles que carecem de condições que, provavelmente, serão tidos como fracassados sendo, por vezes, renegados às margens da sociedade. A desigualdade ao acesso à informação e à educação, especialmente em países subdesenvolvidos e em minorias sociais, permite a manutenção do poder em determinados estratos sociais instituídos (Santos et al., 2016). Tal dinâmica corrobora a geração e perpetuação de relações de trabalho terceirizadas, precárias e mal remuneradas, fenômeno contemporâneo descrito como a uberização do trabalho (Slee, 2019). 
PEDROSA, Matheus; MELLO, Ruth Espínola Soriano de. Da competição à cooperação: Economia Solidária como proposta sustentável para os novos rumos da humanidade.

O paradigma atual parece valorizar demasiadamente o eu, não o coletivo. Por conseguinte, o egoísmo tende a ser considerado o princípio básico para vida em comunidade. Provavelmente a sociedade seria mais fraterna se, ao invés de valorizar o individualismo, a disputa e a competição, o paradigma fosse pautado em comportamentos altruístas guiados pela colaboração. Essa proposição pode parecer utópica, porém, os comportamentos altruístas também ocorrem na natureza e estão presentes em nossa árvore filogenética.

\section{O altruísmo}

Ao longo dos anos, diversos biólogos, psicólogos e neurocientistas se debruçaram sobre o desafio do estudo dos comportamentos altruístas, citados também como pró-sociais. Buscando solucionar uma das maiores questões de sua teoria, a explicação de Darwin para o altruísmo era que, ao passo que ocorre uma desvantagem com determinado individuo, é provável que haja uma vantagem no coletivo (Darwin, 1859). Entretanto, essa afirmação não explica eventos importantes, incluindo comportamentos complexos humanos em sociedade. Atualmente, de acordo com a literatura científica, o altruísmo está ligado à noção de parentesco, similaridade e reciprocidade (Fehr \& Fischbacher, 2003). Ou seja, há uma tendência de colaborar com aqueles que são semelhantes ou pertencentes ao mesmo grupo e que podem retribuir a ajuda em momento oportuno no futuro. A essa dimensão da ajuda para ser ajudado, o antropólogo e biólogo Robert Trivers (2006) cunhou o termo altruísmo recíproco, explicando que para a existência em grupo é necessário que haja cooperação.

No momento, a ciência divide, com certa uniformidade, os comportamentos altruístas em três dimensões: altruísmo recíproco, punição altruísta e gratificação altruística (Fehr \& Fischbacher, 2003). De modo resumido, o primeiro seria a dimensão da ajuda para ser ajudado, o segundo estaria relacionado à justiça social como um modo de evitar injustiças e, por fim, a gratificação seria uma forma de agradecimento por um comportamento colaborativo anterior. Os autores ressaltam que o senso de justiça é um importante fator do altruísmo, visto que esse não tem um objetivo egoísta, estando diretamente relacionado ao cuidado com o outro e à preocupação com a estabilidade e perenidade da comunidade (Fehr \& Fischbacher, 2003; Trivers, 2006). Essa afirmação, talvez, ajude a explicar o porquê de a percepção de injustiça ser uma das sensações que mais motiva os seres humanos na busca por mudanças. Afinal, as injustiças e desigualdades não são naturais. 
Apesar dos avanços, ainda hoje, a ciência carece de dados para explicar cientificamente os comportamentos altruístas em humanos dada a complexidade do tema. Todavia, já é reconhecida a importância da cultura e do meio no que se refere a esses comportamentos. Segundo Fehr e Fischbacher (2003), uma minoria de sujeitos altruístas podem forçar a maioria de egoístas a colaborarem e vice-versa. Além disso, estudos utilizando a técnica de ressonância magnética funcional observaram ativação em circuitos dopaminérgicos relacionados ao sistema de recompensa cerebral nos participantes que tiveram comportamentos de cooperação mútua (Rilling et al., 2002). Ou seja, ajudar também faz bem para quem ajuda.

Evolutivamente, o filhote humano é um dos mais frágeis e dependentes de todo reino animal, pois caso seja abandonado pelos cuidadores a chance de sobrevivência do bebê é próxima de zero. Harari (2018) utiliza essa constatação para remontar a importância da comunicação e união dos seres humanos em tribos para a evolução da espécie. Segundo o autor, o apoio social age como protetor à vida permitindo a socialização, o que ajuda na passagem de ensinamentos e técnicas, tendo sido de grande relevância para evolução dos Sapiens. Curiosamente, não são só os humanos que se constituem em sociedades, alguns insetos se organizam de um modo altamente complexo estudado pela biologia como eussocialidade. Como exemplo, se pode citar as abelhas que dividem o trabalho, compartilham o cuidado da prole e coexistem com diversas gerações. Nessas comunidades, além da hierarquia, há um importante fator genético para a presença dos comportamentos altruístas e colaborativos (Nowak, Tarnita \& Wilson, 2010). Analogamente, o dito popular "uma mão lava a outra" poderia figurar como exemplo de altruísmo, pois, nele, há uma relação de dependência mútua entre as mãos o que demonstra a necessidade do semelhante para a efetivação de determinado fim. Nesse sentido, tendo em vista que o humano é um ser gregário e dependente, não haveria existência sem o outro. Porém, na atualidade, a sociedade de mercado parece ensinar o oposto: deve-se buscar a realização solitária e individual, assim o grupo e a comunidade perdem relevância ao passo que o indivíduo é valorizado pela sua performance e imagem (Debord, 1991).

Vale ressaltar que a biologia e cultura interferem entre si mutuamente, não se busca entender somente os aspectos biológicos do altruísmo, mas também sua implicação no ambiente social. Em outras palavras, é preciso manter a parcimônia na busca pelo não determinismo, evitando os reducionismos sejam esses de ordem biológica, psicológica sejam de ordem social. O intuito deste estudo não é analisar acuradamente o altruísmo e seus impactos, mas sim 
PEDROSA, Matheus; MELLO, Ruth Espínola Soriano de. Da competição à cooperação: Economia Solidária como proposta sustentável para os novos rumos da humanidade.

Dignidade Re-Vista, v.6, n.11, dez 2020.

apresentar a sua noção como importante estratégia de mudança de comportamental individual, tendo, portanto, potencial para transformações sociais.

\section{A economia solidária}

De acordo com Paul Singer (2002), a cooperação é uma das principais características da economia solidária, além disso, segundo ele, a competição e cooperação são incompatíveis entre si. A economia solidária (ou economia social) é pautada em práticas que visam os sujeitos e o ambiente, buscando a qualidade de vida redefinindo as relações entre economia e sociedade (Santos et al., 2016). Em vista disso, valoriza práticas colaborativas e sustentáveis pautadas em modelos de autogestão, ou seja, sem níveis de hierarquização no trabalho (heterogestão) o que auxilia na repartição das riquezas de modo justo (Singer, 2002). A economia solidária foi criada no final do século passado, momento em que diversos países enfrentavam crises sociais e econômicas, e na atualidade está em expansão, majoritariamente, com o apoio da sociedade civil, trabalhadores, universidades e intelectuais.

Paul Singer (1932-2018) apresenta a economia solidária como alternativa ao modelo vigente, já que o capitalismo preza pela competição, o que respalda e incentiva a divisão e polarização social em grupos na dinâmica de "nós contra eles". Sobre essa questão, cabe sublinhar que, conforme já citado, a noção de pertencimento e unidade social aumenta a probabilidade de comportamentos altruístas. Porém, o modelo atual suscita uma tendência a supervalorização do indivíduo, ser indivisível e autônomo, mas dependente das necessidades de consumo. Cabe ressaltar a problemática na noção de indivíduo, pois sempre há o sujeito em comunidade, em relação ao meio existindo em um determinado tempo em uma determinada sociedade: em conjunto. E é essa dimensão que a economia social busca reativar na sociedade, a noção do grupo e do trabalho cooperativo de modo mútuo e compartilhado.

Contudo, o atual sistema, na busca pelo desenvolvimento, tende a acentuar as desigualdades. Sobre esta dinâmica paradoxal, Paul Singer apresenta, nas primeiras páginas de uma de suas obras, a problemática da competição no modelo capitalista:

O capitalismo se tornou dominante há tanto tempo que tendemos a tomá-lo como normal ou natural. O que significa que a economia de mercado deve ser competitiva em todos os sentidos: cada produto deve ser vendido em numerosos locais, cada emprego deve ser disputado por numerosos pretendentes, cada vaga na universidade deve ser disputada por numerosos vestibulandos, e assim por diante. A competição é boa de dois pontos de vista: ela permite a todos nós consumidores escolher o que mais nos satisfaz pelo menor preço; e ela faz com que o melhor 
vença, uma vez que as empresas que mais vendem são as que mais lucram e mais crescem, ao passo que as que menos vendem dão prejuízo e se não conseguirem mais clientes acabarão por fechar. (Singer, 2002, p.7)

Nessa passagem, Singer pondera que a competição é positiva para economia, pois impulsiona as empresas a buscarem novas tecnologias e inovações, além de reduzir custos - o que, consequentemente, favorece o consumidor. No entanto, existe um impacto social da cultura da competição que é pouco observado: "A apologia da competição chama a atenção apenas para os vencedores, a sina dos perdedores fica na penumbra" (Singer, 2002, p.8). Ou seja, aqueles que perdem tendem a serem associados ao fracasso e colocados às margens da sociedade, o que pode gerar um ciclo de exclusão e segregação. Dessa forma, a economia social também seria um modo de reinserção e de oportunidades àqueles que não são selecionados por não adequação às exigências e metas do modelo vigente. Isto é, a economia solidária busca respostas às questões que o capitalismo entende como inerentes ao modelo, portanto, irresolvíveis.

A proposição de economia solidária, cooperação e altruísmo pode parecer utópica para alguns, no entanto, hoje já existem bons exemplos de empreendimentos e empresas sociais (baseadas na economia solidária) que impactam positivamente a vida de milhares de pessoas. Como exemplo se pode citar os bancos comunitários que permitem a reorganização das economias locais pela circulação de riqueza em moeda própria, incentivando uma rede local de produção e consumo. Tais iniciativas representam um importante impacto na melhoria da qualidade de vida de comunidades carentes ou regiões que sofriam com ausência de recursos ou altos níveis de desigualdade. E, para além dos bancos sociais, existem iniciativas intercontinentais de incentivo a empreendimentos sociais baseados na economia solidária, já que essa é uma prática mundial não estando restrita somente ao Brasil ou à América Latina. Seguindo o exemplo de outros países, no ano de 2019, o Senado brasileiro aprovou a Política Nacional de Economia Solidária (PNES). O plano propõe diretrizes e requisitos para o reconhecimento legal de organizações solidárias, além de estabelecer estratégias para o incentivo de empreendimentos baseados na economia solidária no país.

Por fim, pode-se citar a iniciativa do Butão, pequeno país na Ásia meridional, propondo a métrica da Felicidade Interna Bruta (FIB) em oposição ao Produto Interno Bruto (PIB). A proposta estabelece métricas que devem ser medidas de acordo com as necessidades básicas da população do país, como saúde, educação, renda, liberdade de expressão, entre outros fatores. Foi desenvolvido tendo como base a premissa que o objetivo central de toda sociedade deveria ser o progresso material associado ao desenvolvimento psicológico, cultural, espiritual, além 
do contato e preservação do meio ambiente (Burns, 2011). Logo, o FIB permite uma análise holística do desenvolvimento de uma nação, já que nele o desenvolvimento material é apenas um fator dentre os demais. Tal proposição rompe com o paradigma de desenvolvimento ocidental ortodoxo no qual o foco do progresso está nas riquezas materiais geradas por um país.

\section{Considerações finais}

Após a apresentação de algumas teorias clássicas associadas à ideia da sociedade como meio constante de disputa, foram estabelecidas relações entre a noção de competição e cooperação/altruísmo na evolução e na sociedade. A partir da situação atual do aumento das desigualdades no mundo, foram apresentadas algumas diferenças entre o modelo atual de organização social e econômica e os fundamentos básicos da economia solidária, sendo essa última uma possível saída aos desafios contemporâneos relacionados ao acesso a oportunidades no mercado de trabalho, distribuição de renda e redução das desigualdades. No entanto, até o momento, existe pouca literatura relacionada à economia social no Brasil. Em vista disso, é necessário que novos estudos sejam desenvolvidos demonstrando a aplicabilidade e resultados da economia solidária, principalmente, em países em desenvolvimento.

Ademais, é imprescindível que haja engajamento dos psicólogos(as) para a importância do estudo do sujeito em sociedade, tendo a compreensão de que a questão da desigualdade e seus impactos sociais também fazem parte de seus estudos e atuação. Além disso, visto que atualmente existem poucos estudos sobre a economia solidária à luz da ciência psicológica, é necessário que áreas da psicologia contribuam no avanço dessas discussões.

Finalmente, é importante ressaltar que as desigualdades e mazelas sociais não são inerentes à vida e, portanto, não devem ser normalizadas. A cada nova crise é reconhecida a importância da revisão do modelo capitalista, nesse sentido, movimentos sociais desenvolvem iniciativas micro e meso referenciadas para projeção de macroestruturas no enfrentamento do mainstream neoliberal financeiro. Muito mais que um debate ideológico ou intelectual é preciso que ocorra um esforço civil e estatal no combate às desigualdades, redução da pobreza e miséria de forma prática. Nesse sentido, conforme trabalhado, atitudes individuais altruístas e cooperativas podem gerar importantes impactos à comunidade. Porventura, na busca por uma sociedade mais fraterna, haverá a constatação de que a cooperação é mais viável que a competição. 


\section{Referências bibliográficas}

AGÊNCIA SENADO. Política Nacional de Economia Solidária é aprovada no Senado. 2019. Disponível em: https://www12.senado.leg.br/noticias/materias/2019/12/11/politica-nacionalde-economia-solidaria-e-aprovada-no-senado. Acesso em: 12 set 2020.

ALMEIDA, M. C. A função social da empresa na sociedade contemporânea: perspectivas e prospectivas. Argumentum-Argumentum Journal of Law, v.3, p.141-152, 2003.

ALVES, M. D.; NETO, J. C. P. Sofrimento psíquico no trabalho e estresse ocupacional em professores: causas e consequências. Psicologia e Educação On-Line, v.2, n.2, p.40-46, 2019.

BURNS, G. W. Gross National Happiness: a gift from Bhutan to the world. Positive psychology as social change. Springer, Dordrecht, p.73-87, 2011.

CARVALHO, L. Desemprego e desigualdade. Jornal Folha de São Paulo. 2019. Disponível em: $\quad$ https://www1.folha.uol.com.br/colunas/laura-carvalho/2019/05/desemprego-edesigualdade.shtml. Acesso em: 17 ago 2020.

CRELIER, C. PNAD Contínua: taxa de desocupação é de 13,3\% e taxa de subutilização é de 29,1\% no trimestre encerrado em junho de 2020. Estatísticas Sociais, Agência IBGE. 2020. Disponível em: https://agenciadenoticias.ibge.gov.br/agencia-sala-de-imprensa/2013-agenciade-noticias/releases/28478-pnad-continua-taxa-de-desocupacao-e-de-13-3-e-taxa-desubutilizacao-e-de-29-1-no-trimestre-encerrado-em-junho-de-2020. Acesso em: 19 ago 2020.

DARWIN, C. A origem das espécies. São Paulo: Hemus, 2003 [1859].

DEBORD, G. A sociedade do espectáculo. Rio de Janeiro: Contraponto, 1997.

FEHR, E.; FISCHBACHER, U. The nature of human altruism. Nature, v.425, n.6960, p.785$791,2003$.

FONTANA, R. L. M. et al. Teorias demográficas e o crescimento populacional no mundo. Ciências Humanas e Sociais Unit, v.2, n.3, p.113-124, 2015.

G1. Desigualdade de renda no Brasil atinge o maior patamar já registrado, diz FGV/IBRE. 2019. Disponível em: https://g1.globo.com/economia/noticia/2019/05/21/desigualdade-derenda-no-brasil-atinge-o-maior-patamar-ja-registrado-diz-fgvibre.ghtml. Acesso em: 12 set 2020.

GOODWIN, C. J. História da psicologia moderna. São Paulo: Cultrix, 2005.

HARARI, Y. N. Sapiens: uma breve História da Humanidade. Porto Alegre: L\&PM, 2018.

NOWAK, M. A.; TARNITA, C. E.; WILSON, E. O. The evolution of eusociality. Nature, v.466, n.7310, p.1057-1062, 2010. 
OXFAM BRASIL. Bilionários do mundo têm mais riqueza que $60 \%$ da população mundial. 2020. Disponível em: https://www.oxfam.org.br/noticias/bilionarios-do-mundo-tem-maisriqueza-do-que-60-da-populacao-mundial/. Acesso em: 12 set 2020.

PEREIRA, A. J.; MARIN, S. Lei da escassez e comportamento econômico: uma leitura institucional. Revista Econômica, v.18, n.2, 2017.

RILLING, J. K. et al. A neural basis for social cooperation. Neuron, v.35, n.2, p.395-405, 2002.

SANTOS, C. S. et al. Psicologia \& economia solidária: Possíveis intervenções. Diálogo, n.31, p.47-57, 2016.

SINGER, P. Introdução à Economia Solidária. São Paulo: Fundação Perseu Abramo, 2002.

SLEE, T. Uberização: a nova onda do trabalho precarizado. São Paulo: Elefante, 2019.

TRIVERS, R. Reciprocal altruism: 30 years later. In: KAPPELER, P. M.; VAN SCHAIK, C. P. Cooperation in primates and humans. Springer-Verlag Berlin Heidelberg, p.67-83, 2006. 